\title{
O controle de Convencionalidade na Relação Intersistêmica entre o Sistema Interamericano de Direitos Humanos e os Sistemas Nacionais de Direitos Humanos Desafios em Cenários de Interseções Variadas
}

\author{
Pedro Henrique de Faria Barbosa \\ Doutorando em Direito do Comércio Internacional pela Universidade Federal de Pernambuco (2016). \\ Mestrado em Direitos Humanos pela Universidade Federal de Pernambuco (2015). Graduação em Direito pela Universidade \\ Federal de Pernambuco (2009). pedrohfb@hotmail.com

\section{Sylvio Loreto} \\ Graduação em Direito pela Universidade Federal de Pernambuco (1952). Doutorado em Direito pela Universidade Federal \\ de Pernambuco (1954). Professor titular da Universidade Federal de Pernambuco. Possui experiência na área de Direito, com \\ ênfase em Direito Internacional Privado, atuando principalmente nos seguintes temas: Direito Internacional Privado, Legislação \\ sobre estrangeiro e princípios aplicáveis, Direito Internacional. Líder do grupo de pesquisa "Integração regional, globalização \\ e Direito Internacional". sylvioloreto@uol.com.br
}

O presente artigo insere-se no campo de estudo dos direitos humanos, focando-se na aplicação do controle de convencionalidade por parte da Corte Interamericana de Direitos Humanos e dos tribunais internos dos Estados-membros do Sistema Interamericano de Direitos Humanos. Seu objetivo principal é a análise dos desafios para a instituição de tal controle em um cenário de interação intersistêmica. Quanto à metodologia, a análise é desenvolvida inicialmente por meio de uma abordagem linguística das definições de certos termos de direitos humanos por parte da doutrina internacional, prosseguindo para uma abordagem histórico-jurídica da consolidação do Sistema Interamericano de Direitos Humanos e da Corte Interamericana de Direitos Humanos. Na sequência são feitas considerações sobre possíveis resultados da relação intersistêmica entre o contexto regional e nacional, quanto à aplicação do controle de convencionalidade, apontando os níveis de interseção existentes entre os distintos sistemas. Desse estudo resultam as conclusões no sentido dos desafios para a efetiva aplicação do controle de convencionalidade por parte dos tribunais internos dos Estados americanos e de caminhos possíveis para o incremento do diálogo intersistêmico. Palavras-chave: Sistema Interamericano de Direitos Humanos. Corte Interamericana de Direitos Humanos. Controle de convencionalidade. Relação intersistêmica. Interseções.

THE CONTROL OF CONVENTIONALITY IN THE INTERSYSTEMIC RELATIONSHIP BETWEEN THE INTER-AMERICAN HUMAN RIGHTS SYSTEM AND THE NATIONAL HUMAN RIGHTS SYSTEMS - CHALLENGES IN SCENARIOS OF VARIED INTERSECTIONS

\section{ABSTRACT}

The present article is inserted in the field of study of human rights, focusing in the application of the control of conventionality by the Inter-American Human Rights Court and internal courts of Member-States of the Inter-American Human Rights System. Its main objective is to analyze the challenges to implement of such control in a intersystemic interaction scenario. About methodology, such analysis is initially developed through a linguistic approach of definitions of certain human rights terms by the international doctrine, proceeding to a legal-historical approach of the consolidation of the Inter-American Human Rights System and the Inter-American Human Rights Court. In sequence, considerations are made about possible results of the intersystemic relation between national and regional context about the application of the control of conventionality, pointing existent intersection points levels between the distinct systems. From such study results the conclusions in the sense of the challenges for the effective application of the control of conventionality by the internal court of American States and of possible paths to increase the intersystemic dialogue.

Keywords: Inter-American Human Rights System. Inter-American Human Rights Court. Control of conventionality. Intersystemic relations. Intersections.

\section{SUMÁRIO}

1 Introdução. 2 O Sistema Interamericano de Direitos Humanos como sistema internacional - questão terminológica. 2.1 Regime x Sistema. 2.2 Sistema Global x Sistema Internacional. 2.3 Direitos Humanos x Direitos Fundamentais. 3 O Sistema Interamericano de Proteção de Direitos Humanos. 3.1 A Corte Interamericana de Direitos humanos. 40 Controle de Convencionalidade. 4.1 Controle de Convencionalidade quando não há interseção direta entre sistemas. 4.2 Controle de Convencionalidade quando um sistema é subsistema de outro. 4.3 Controle de Convencionalidade quando há interseção entre sistemas. 5 Considerações Finais. 6 Referências. 


\section{INTRODUÇÃO}

Os direitos humanos são um ramo do Direito que tem passado por profundas alterações nas últimas décadas. Desde o final da Segunda Guerra Mundial e a criação da Organização das Nações Unidas, mas, principalmente, com as mudanças do sistema internacional ocorridas no início da década de 90, há uma profunda relação entre o Direito Internacional e os direitos nacionais em matéria de proteção de direitos humanos.

No contexto latino-americano, superando o período de regimes autoritários ocorrido durante as décadas de 50, 60 e 70 do século passado, a onda de redemocratização ocorrida durante a década de 80 e início da década de 90 do século 20 afetou profundamente o Direito Constitucional dos países da região, com o surgimento de diversos novos textos constitucionais. Conforme analisa Flávia Piovesan:

É justamente sob o prisma da reconstrução dos direitos humanos que é possível compreender, no Pós-Guerra, de um lado, a emergência do chamado Direito Internacional dos Direitos Humanos, e, de outro, a nova feição do Direito Constitucional ocidental, em resposta ao impacto das atrocidades então cometidas. No âmbito do Direito Constitucional ocidental, são adotados Textos Constitucionais abertos a princípios dotados de elevada carga axiológica, com destaque para o valor da dignidade humana. Esta será a marca das Constituições europeias do Pós-Guerra. Observe-se que, na experiência brasileira e mesmo latino-americana, a abertura das Constituições a princípios e a incorporação do valor da dignidade humana demarcarão a feição das Constituições promulgadas ao longo do processo de democratização política. Basta atentar à Constituição brasileira de 1988, em particular à previsão inédita de princípios fundamentais, entre eles o princípio da dignidade da pessoa humana (2013, p. 91).

Não apenas a criação de normas e princípios, mas, principalmente, o surgimento de organismos internacionais específicos para proteção, monitoramento e cumprimento dos direitos humanos, tem alterado a forma tradicional de aplicação dos direitos humanos, superando períodos em que a matéria era tratada de maneira soberana por cada Estado. Simultaneamente, antigos organismos de monitoramento passaram por um período de fortalecimento, com a adesão de diversos novos Estados.

A interação entre sistemas jurídicos diversos não é uma questão simples, especialmente quando envolve o tratamento de normas em âmbito constitucional, como é o caso da matéria de direitos humanos. A tradicional hierarquia piramidal, presente em um único ordenamento jurídico, não necessariamente explica a relação entre sistemas, uma vez que nem sempre há relação hierárquica capaz de dirimir conflitos. Esse problema é apontado por Marcelo Neves ao analisar que:

A pergunta concernente à conformidade ou desconformidade ao direito (licitude ou ilicitude), em relação a um mesmo caso, apresenta-se perante uma pluralidade de ordens jurídicas. Essa pergunta vazia pode ser complementada com referência a conteúdo: quais os critérios ou programas condicionais que podem servir para definir se algo se enquadra na hipótese da licitude ou da ilicitude? As diversas ordens, naturalmente, vão invocar, primariamente, os seus modelos de construção de critérios e programas para a resolução de casos. Sem dúvidas, em princípio, a tendência é o surgimento de colisões. O problema reside exatamente na incompatibilidade das possíveis soluções apresentadas. Daí por que a busca de "pontes de transição" é fundamental. Evidentemente, essas "pontes", como 
modelos de entrelaçamentos que servem a uma racionalidade transversal entre ordens jurídicas, não são construídas de maneira permanente e estática no âmbito dinâmico do transconstitucionalismo (2009, p. 128).

Assim, as chamadas colisões entre as diversas ordens não podem ser dirimidas de forma semelhante às colisões dentro de um único sistema. A criação de pontes e o surgimento de uma conversação constitucional reveste-se de relevância não apenas no plano teórico, mas, principalmente, para solucionar conflitos concretos que porventura surjam.

O diálogo para a construção de pontes entre os sistemas é, talvez, o principal mecanismo para a solução de paradoxos. É sabido, porém, que tal diálogo depende da capacidade de compreensão de conceitos de maneira semelhante. A linguagem de cada sistema, especialmente em se tratando de direitos humanos, tema repleto de conceitos abertos e definições abrangentes, é profundamente influenciada por seu contexto cultural, de modo que há colisões, não apenas no que se refere ao âmbito normativo, mas, principalmente, na interpretação dada aos conceitos jurídicos pelos órgãos jurisdicionais de cada sistema.

No contexto regional americano é conhecida a importância e influência do Sistema Interamericano de Direitos Humanos na tratativa de direitos humanos no continente. Nesse cenário, um importante ponto de diálogo presente nesse sistema, ressaltado pela atuação de seu órgão jurisdicional, a Corte Interamericana de Direitos Humanos, é a realização do controle de convencionalidade, ferramenta para garantir que haja um respeito por parte dos diversos Estados americanos às normativas convencionais interamericanas.

Apesar da imensa importância do controle de convencionalidade, ainda há certa resistência de diversos Estados em variados níveis de suas administrações em fazer valer o referido controle. Assim, é objetivo do presente trabalho analisar a figura do controle de convencionalidade e os cenários existentes nas relações entre os sistemas de direitos humanos, os quais justificam eventuais aplicações ou rejeições do controle de convencionalidade.

Para isso, deve-se partir de uma análise terminológica da definição do Sistema Interamericano de Direitos Humanos como um sistema internacional, importante para evitar imprecisões terminológicas que prejudicam a compreensão da matéria tratada, para em seguida adentrar em possíveis cenários distintos de interação intersistêmica. A abordagem deste estudo é sempre no sentido de buscar compreender os cenários de possibilidade e desafios para o diálogo intersistêmico no continente americano em matéria de direitos humanos, assunto de grande importância não apenas para os Estados que integram o contexto regional, mas, principalmente, para os indivíduos, destinatários primários das garantias de direitos humanos consolidadas nas últimas décadas.

\section{O SISTEMA INTERAMERICANO DE DIREITOS HUMANOS COMO SISTEMA INTERNACIONAL - QUESTÃO TERMINOLÓGICA}

O objetivo do presente trabalho é analisar o Sistema Interamericano de Direitos Humanos. Apesar de ser amplamente conhecido e empregado por uma respaldada doutrina, por vezes há confusões terminológicas e algumas definições são empregadas como sinonímias, quando na realidade tratam de temas diversos. É necessário, portanto, traçar algumas distin- 
ções entre conceitos muitas vezes utilizados sem grande rigor científico, mesmo por autores de respaldo. Assim, para garantir que a expressão a ser aplicada no trabalho corresponda a uma noção adequada, deve-se prosseguir com uma sucinta diferenciação e delimitação de conceitos como sistema, internacional e a noção de direitos humanos, fazendo um contraponto com outros termos bastante conhecidos e amplamente empregados na doutrina.

\subsection{Regime x Sistema}

Inicialmente, abordando o conceito de regime, é notória sua conceituação por Stephen Krasner, que bem define como “(...) princípios, normas e regras implícitos ou explícitos e procedimentos de tomada de decisões de determinada área das relações internacionais em torno dos quais convergem as expectativas dos atores" (KRASNER, 1982, p. 2, tradução nossa). ${ }^{1}$ A concepção de regime, portanto, envolve aplicação de regras e princípios por atores internacionais. Exemplo disso é a noção de regime internacional de direitos humanos, em que atores diversos (Estados, organizações internacionais, indivíduos) interagem entre si baseados em uma série de normativas.

Na doutrina do Direito há uma ampla utilização do termo sistema para definir uma série de comunicações entre normas e atores, a exemplo de sistema jurídico, sistema mundial de comércio, entre outros. A difusão da noção de sistemas está intimamente relacionada com a difusão e aceitação da doutrina jurídica da Teoria Geral dos Sistemas Sociais de Niklas Luhmann (LUHMANN, 2016). Sem aprofundar-se na teoria em si, há uma maior aceitação, por parte da doutrina, do emprego do termo sistema quando se refere a uma série de formas de interação e organização, por se tratar de um termo mais amplo, o qual não necessariamente preocupa-se em considerar se se trata de algum âmbito das relações internacionais, como é o caso de regimes.

Desse modo, adentrando nomeadamente na temática dos direitos humanos, é compreensível que haja uma predileção doutrinária por definir arranjos na matéria como sistemas, principalmente quando se trata de relações em que há uma pluralidade de atores sem uma necessária priorização do aspecto internacional das relações. Não por acaso, portanto, quando se fala em arranjos locais ou regionais, é mais empregada a noção de sistema, a exemplo do Sistema Interamericano de Direitos Humanos.

Ainda assim, definida a escolha pela terminologia sistema, quando se trata de matérias que ultrapassam as fronteiras nacionais de um Estado, há também algumas dúvidas quanto a sua definição. Sistemas globais (ou mundiais) muitas vezes são empregados como noções semelhantes de sistemas internacionais, de modo que é necessário considerar até que ponto é possível, de fato, aplicar indistintamente os termos.

\subsection{Sistema Global x Sistema Internacional}

Apesar de análogos, o termo global (o qual é costumeiramente empregado como sinônimo de mundial) e o termo internacional possuem concepções, apesar de próximas, distintas em pontos importantes. Seguindo uma concepção mais próxima dos verbetes no pró-

\footnotetext{
No original: “(...) sets of implicit or explicit principles, norms, rules, and decision-making procedures around which actors' expectations converge in a given area of international relations".
} 
prio dicionário, o conceito de global/mundial traz consigo uma carga de englobar o planeta como um todo, sem deixar de incluir qualquer local ou indivíduo. Assim, quando se fala em sistema global de direitos humanos, pressupõe-se uma noção de universalidade (também por isso em situações específicas é aplicado como sinônimo de universal) na abrangência desse sistema, sem estar adstrita a um Estado específico ou a um grupo de indivíduos.

A noção de internacional, outrossim, também possui uma concepção abrangente, porém bem mais limitada. Em verdade, a prefixação do termo traz a noção de relação entre nacionais, ou seja, algo que vai além do limite de uma nação, podendo tanto se limitar a dois ou três atores nacionais distintos quanto chegar ao ponto de abranger todas as nações e, nesse caso, aproximar-se bastante do conceito de global/mundial.

Nesse cenário, a utilização da terminologia sistema internacional é muitas vezes recomendada para delimitar sistemas sociais que ultrapassam as fronteiras de uma única nacionalidade, porém não necessariamente possuem a universalidade de abrangência do sistema global, como poderia ser, por exemplo, o sistema global de direitos humanos da Organização das Nações Unidas (ONU). Mais que isso, quando se trata de um sistema internacional de abrangência regional, como é o caso do Sistema Interamericano de Direitos Humanos, seria em verdade uma imprecisão tentar defini-lo como um sistema global, pois em verdade trata-se de uma esfera de influência internacional, de âmbito regional.

\subsection{Direitos Humanos x Direitos Fundamentais}

Por fim, talvez uma distinção que ainda cause debates nos dias atuais é a definição clara das diferenças entre direitos humanos e direitos fundamentais. Ambos, sem dúvidas, podem referir-se a uma dimensão de direitos básicos que os indivíduos dispõem para concretizar as garantias mais básicas de sua vida e exercer a cidadania, porém há, por vezes, o questionamento acerca da real abrangência de cada um.

Parte significativa da doutrina convencionou em considerar que os direitos humanos seriam designados para direitos básicos previstos na esfera internacional, enquanto os direitos fundamentais seriam a concretização de tais direitos dentro dos limites nacionais, sob a regência de um ordenamento jurídico interno, por exemplo, quando são previstos em um texto constitucional.

Apesar de ser uma definição sucinta e ainda muito empregada, ela traz uma série de questões, por exemplo, qual seria a definição a ser empregada quando um grupo de direitos humanos previstos na esfera internacional são internalizados em um ordenamento nacional, tornando-se, portanto, norma interna, como é exemplo, no caso brasileiro, dos decretos que promulgam tratados internacionais. Mais que isso, há uma tendência à consolidação de uma via de mão dupla entre os ordenamentos jurídicos nacionais e os sistemas internacionais de direitos humanos, em que ocorre uma influência recíproca que permite que conceitos, princípios e mesmo normas sejam absorvidos tanto da via internacional para a nacional quanto na via inversa.

Nesse cenário, é difícil definir com clareza qual seria o limiar para deixar de tratar determinados temas como direitos humanos, para ingressar no rol de direitos fundamentais. Há a preferência, portanto, por incluir a terminologia direitos humanos quando se faz presente 
a influência internacional no referido direito, quer seja na sua concepção, normatização ou aplicação. Desse modo, quando se fala de interpretação de cortes internacionais, está sendo aplicada a dimensão dos direitos humanos.

Abordada essa questão terminológica, é possível compreender melhor a escolha pela definição do Sistema Interamericano de Direitos Humanos como o é, inclusive considerando sua natureza de sistema - ou seja, uma série de comunicações - internacional - de modo que ultrapassa as fronteiras de um único país - e de direitos humanos - em que o elemento internacional faz-se presente não apenas na formulação dos direitos, mas também em sua aplicação. Ultrapassada essa questão, é possível ingressar no Sistema Interamericano em si, considerando sua formação e consolidação, bem como eventuais influências desse processo na realização do controle de convencionalidade e em que níveis ele vem a ocorrer.

\section{O SISTEMA INTERAMERICANO DE PROTEÇÃO DE DIREITOS HUMANOS}

A proteção dos direitos humanos é realizada por diversos organismos, nacionais ou internacionais, o que permite uma maior abrangência e efetividade na sua efetivação. No âmbito internacional, a matéria não se limita ao sistema global de proteção, conduzida primariamente pela ONU, sendo complementada por sistemas regionais de proteção de direitos humanos.

A existência de diversas esferas, com abrangências distintas, não deve ser considerada um estímulo a conflitos, pois, ao contrário do que uma análise apressada apontaria, a multiplicidade de sistemas específicos contribui para a constituição de um sistema de proteção geral mais robusto. A proximidade geográfica e as similitudes culturais existentes dentro de uma região permitem que os sistemas regionais de proteção de direitos humanos complementem de forma bastante efetiva o sistema global. Assim afirmam Christof Heyns e Frans Viljoen, ao analisarem que:

Enquanto o sistema global de proteção dos direitos humanos geralmente sofre com a ausência de uma capacidade sancionatória que têm os sistemas nacionais, os sistemas regionais de proteção dos direitos humanos apresentam vantagens comparativamente ao sistema da ONU: podem refletir com maior autenticidade as peculiaridades e os valores históricos de povos de uma determinada região, resultando em uma aceitação mais espontânea e, devido à aproximação geográfica dos Estados envolvidos, os sistemas regionais têm a potencialidade de exercer fortes pressões em face de Estados vizinhos, em caso de violações. (...) Um efetivo sistema regional pode conseqüentemente complementar o sistema global em diversas formas (HEYNS; VILJOEN, 1999, p. 423).

De forma semelhante ao que ocorre na relação entre o sistema nacional e o internacional, não há uma oposição entre o sistema internacional global e o regional. Em verdade observa-se, cada vez mais, uma interpenetração bastante benéfica entre os âmbitos nacional, regional e global no que se refere à promoção e proteção dos direitos humanos. Não apenas a criação de normas de promoção de direitos humanos e o monitoramento de violações, mas, principalmente, o surgimento e a crescente abrangência dos tribunais de direitos humanos, nos quais, cada vez mais, há a presença dos indivíduos, o que tem fortalecido a instituição dos direitos humanos em diversos Estados. 
No contexto regional do continente americano verifica-se a existência do sistema regional conhecido como Sistema Interamericano de Proteção de Direitos Humanos. Esse sistema surgiu no âmbito da Organização dos Estados Americanos, organização internacional criada em 1948, sendo efetivada, principalmente, com a elaboração da Convenção Americana de Direitos Humanos, também denominada Pacto de San José da Costa Rica, de 1969.

Fazendo uma breve retomada histórica da criação e consolidação do Sistema Interamericano, verifica-se que, inicialmente, quando da criação da OEA, é elaborada a Declaração Americana dos Direitos e Deveres do Homem, em abril de 1948, aprovada na IX Conferência Americana em Bogotá, no contexto do pós-Segunda Guerra Mundial. É notável analisar que o Sistema Interamericano previu princípios de proteção dos direitos humanos antes mesmo do contexto global, uma vez que a Declaração Americana precede a Declaração Universal dos Direitos Humanos da ONU, de dezembro de 1948.

A Declaração Americana estabelece 28 direitos e 11 deveres dos cidadãos americanos. Como a maioria das declarações internacionais, o acordo prevê normativas, que constituem princípios, os quais são dotados de alto grau de generalidade e abstração, e não obrigações jurídicas em sentido estrito. Ainda assim, contribuiu como marco inicial e fonte principiológica que se adensaria com a Convenção Interamericana de Direitos Humanos.

Posteriormente é elaborado o Pacto de San José da Costa Rica durante a Conferência Especializada Interamericana de Direitos Humanos, de novembro de 1969, vindo a entrar em vigor em 1978. A adesão ao Pacto de San José não abrangeu todos os membros da OEA - EUA e Canadá não são parte da Convenção - e houve diversas adesões posteriores. Diferente da Declaração Americana, a Convenção Interamericana impôs deveres aos Estados, uma vez que reconhece a obrigação dos Estados de respeitar direitos e liberdades presentes na Declaração e de adotar posições de Direito interno que sejam necessárias para garantir a realização desses direitos.

Elenca os direitos humanos das Américas, semelhantes aos direitos universais: vida, personalidade jurídica, liberdade, integridade pessoal, proibição da escravidão e servidão, liberdade pessoal, garantias judiciais, princípio da legalidade e irretroatividade dos direitos humanos, indenização, proteção da honra e dignidade, liberdade de consciência e religião, liberdade de expressão, resposta e retificação, reunião, associação, proteção à família, nome, criança, direito à nacionalidade, propriedade privada, circulação de residência, direitos políticos, igualdade perante a lei, proteção judicial, direitos econômicos, sociais e culturais. ${ }^{2}$

Adicionalmente ao Pacto de San José foram elaborados dois protocolos: o Protocolo de San Salvador, de 1988, referente aos direitos econômicos, sociais e culturais, e o Protocolo de Abolição da Pena de Morte, de 1990. A esses Protocolos somam-se as convenções interamericanas setoriais, como a Convenção Interamericana para Prevenir e Punir a Tortura, de 1985; a Convenção Interamericana para Prevenir, Punir e Erradicar a Violência contra a Mulher, de 1994; a Convenção Interamericana sobre o Desaparecimento Forçado de Pessoas, de 1994, e a Convenção Interamericana sobre a Eliminação de Todas as Formas de Discriminação contra

2 Para maior detalhamento, ver artigos 3o ao 25 da Convenção Americana sobre Direitos Humanos. Disponível em: http:// www.oas.org/dil/esp/tratados_B-32_Convencion_Americana_sobre_Derechos_Humanos.pdf. 
Pessoas Portadoras de Deficiências, de 1999. Houve também, em 2013, a elaboração da Convenção Contra Toda Forma de Discriminação e Intolerância e da Convenção Contra Racismo, Discriminação Racial e Formas Relacionadas de Intolerâncias.

Dois órgãos foram designados para salvaguardar o Pacto de San José e o Sistema Interamericano de Proteção de Direitos Humanos: a Comissão Interamericana de Direitos Humanos, criada em 1959, e a Corte Interamericana de Direitos Humanos, que iniciou seus trabaIhos em 1979. Ambos funcionam de maneira complementar, com a Comissão constituindo a etapa preliminar para que se possa acionar a jurisdição da Corte. Conforme mencionado anteriormente, o sistema regional atua de forma integrada aos sistemas nacionais de direitos humanos, sendo acionado apenas quando não há solução à questão de direitos humanos dentro do Estado. Sobre isso, analisa Manuel Eduardo Góngora-Mera:

O sistema interamericano de direitos humanos está estruturado judicialmente em dois grandes níveis: um nível nacional que se baseia na obrigação de cada Estado de garantir os direitos e liberdades reconhecidos nos instrumentos interamericanos de direitos humanos, assim como de condenar e reparar as violações a estes direitos. Se um caso concreto não é solucionado neste nível, a Convenção Americana sobre Direitos Humanos (adiante Convenção Americana), contempla um nível regional - de potencial alcance hemisférico - que opera inicialmente em uma instância semijudicial a cargo da Comissão Interamericana de Direitos Humanos; se o caso ainda não é resolvido satisfatoriamente, passa ao conhecimento da Corte Interamericana de Direitos Humanos (adiante Corte Interamericana ou CortelDH).

Descrito nestes termos, o nível regional representa uma proteção subsidiária, coadjuvante e complementar da que oferece o direito interno dos Estados membros do sistema, porque não opera independentemente das instâncias nacionais (GÓNGORA-MERA, 2013, p. 312-313, tradução nossa). ${ }^{3}$

A Corte Interamericana requer que o Estado reconheça expressamente sua jurisdição. É importante frisar que, ademais de atuar como um mecanismo de proteção subsidiário, complementar ao Direito interno dos Estados, a Corte é um órgão jurisdicional que emite sentenças, as quais possuem caráter vinculante para seus membros. Assim, verifica-se que o Sistema Interamericano complementa os sistemas nacionais dos Estados americanos em matéria de direitos humanos. Nesse contexto, a atuação de seus dois órgãos é um dos principais mecanismos para garantir e fortalecer o sistema, especialmente as decisões da Corte Interamericana, de caráter jurisdicional.

\footnotetext{
No original: "El sistema interamericano de derechos humanos está estructurado judicialmente en dos grandes niveles: un nivel nacional que se basa en la obligación de cada Estado de garantizar los derechos y libertades reconocidos en los instrumentos interamericanos de derechos humanos, así como de condenar y reparar las violaciones a estos derechos. Si un caso concreto no es solucionado en este nivel, la Convención Americana sobre Derechos Humanos (en adelante Convención Americana), contempla un nivel regional - de potencial alcance hemisférico - que opera inicialmente en una instancia semijudicial a cargo de la Comisión Interamericana de Derechos Humanos; si el caso aún no es resuelto satisfactoriamente, pasa a conocimiento de la Corte Interamericana de Derechos Humanos (en adelante Corte Interamericana o CortelDH).

Descrito en estos términos, el nivel regional representa una protección subsidiaria, coadyuvante y complementaria de la que ofrece el derecho interno de los Estados miembros del sistema, por lo que no opera independientemente de las instancias nacionales".
} 
O Sistema Interamericano possui uma amplitude normativa de certa robustez, como é possível constatar pelo número de pactos e convenções que o integram, de modo que, ao reconhecer a jurisdição de um Tribunal Internacional capaz de emitir decisões sobre essas normas, o Estado está demonstrando um compromisso claro com a promoção dos direitos humanos, não apenas com seus vizinhos no âmbito regional, mas também com os indivíduos de sua população. O cumprimento desse corpo normativo é, em grande medida, assegurado por meio da atuação da Corte Interamericana de Direitos Humanos, a qual consagra a necessidade de realização pelos Estados do chamado controle de convencionalidade, em que é buscada a adequação dos ordenamentos jurídicos nacionais junto as normas das convenções interamericanas. A criação e a atuação da Corte, portanto, veio para consolidar o Sistema Interamericano e permitir uma interação mais profunda dos Estados com esse Sistema.

\subsection{A Corte Interamericana de Direitos Humanos}

A Corte Interamericana de Direitos Humanos é um órgão judicial autônomo vinculado ao Sistema Interamericano de Direitos Humanos. Criada por meio da Convenção Americana de Direitos Humanos, a Corte foi estabelecida e organizada quando a referida Convenção entrou em vigor, em 1979, período em que a Corte iniciou seu funcionamento. É necessário que o Estado reconheça a jurisdição da Corte para que possa ser julgado. Com sede em San José da Costa Rica, a jurisdição da Corte, até o presente momento, é reconhecida por 22 dos 25 Estados-partes do Pacto de San José.

O funcionamento da Corte Interamericana foi definido por meio de seu Estatuto de 1979 e aprimorado por meio do Regulamento de novembro de 2009. Ela reúne-se seis vezes por ano, em quatro sessões ordinárias e duas extraordinárias. É composta de sete juízes eleitos pela Assembleia Geral da OEA para um mandato de seis anos, com a prorrogação sendo possível por uma única vez. Não deve haver dois juízes de mesma nacionalidade. Caso o mandato de um juiz acabe antes de findo um caso, ele continua a participar deste até seu término. Os juízes eleitos são indivíduos de alta autoridade moral e reconhecido saber em matéria de direitos humanos, cuja atuação na Corte é desvinculada de seu país de origem.

Duas são as principais funções da Corte Interamericana: a emissão de opiniões consultivas e a competência jurisdicional. Sobre as opiniões consultivas, a Corte pode manifestar-se em qualquer matéria de direitos humanos, não se limitando aos Protocolos e Pactos do Sistema Interamericano, interpretando a conformidade da legislação interna dos Estados às normas internacionais de direitos humanos.

A importância das opiniões consultivas é premente para a harmonização do Sistema Interamericano de Direitos Humanos, pois, mesmo não possuindo caráter obrigatório, as opiniões revelam o posicionamento da Corte em matéria de direitos humanos antes mesmo que surja um eventual conflito no Estado, de modo a garantir uma adequação prévia. Apenas Estados podem requerer tais opiniões, mas a matéria a ser tratada é de enorme amplitude, englobando qualquer tema de direitos humanos que porventura possa ser de interesse de um Estado. Acrescentam Louis Hewkin et al.:

Em reposta a uma série de questões postas pelo Governo do Peru, relativamente à jurisdição consultiva da Corte, esta entendeu que tem jurisdição consultiva no que se refere a qualquer previsão atinente à proteção de direitos humanos enunciados em qualquer 
tratado internacional aplicável aos Estados Americanos, independentemente se bilateral ou multilateral, qualquer que seja o propósito principal do tratado, não importando se o Estado não membro do sistema interamericano tem o direito de se tornar parte dele (1993, p. 673).

Ademais da função consultiva, uma das principais características da Corte Interamericana é, por se tratar de um Tribunal Internacional, a sua competência jurisdicional. Ela pode julgar casos de violações de direitos humanos, estabelecidos no Pacto de San José, dos Estados da OEA que reconhecem sua competência contenciosa. Por se tratar de uma competência jurisdicional, as decisões da Corte nesse sentido são vinculantes e possuem plena eficácia perante o Estado.

Apenas os Estados-membros do Sistema Interamericano e a Comissão Interamericana de Direitos Humanos podem levar um caso à atuação contenciosa da Corte Interamericana. Ao contrário do que ocorre na Comissão, a Corte não recebe petições de indivíduos, grupo de pessoas ou Organizações Não Governamentais. O pedido desses pode vir por meio da Comissão, que funciona como órgão de acesso à Corte. Ainda assim, é possível a atuação dos indivíduos, especialmente vítimas e familiares, de forma autônoma, por meio de petições, argumentos e provas referentes ao caso. Conforme exposto no artigo 25,1 , do novo Regulamento da Corte Interamericana:

Artigo 25. Participação das supostas vítimas ou seus representantes

1. Depois de notificado o escrito de submissão do caso, conforme o artigo 39 deste Regulamento, as supostas vítimas ou seus representantes poderão apresentar de forma autônoma o seu escrito de petições, argumentos e provas e continuarão atuando dessa forma durante todo o processo. ${ }^{4}$

Paralelamente a essa garantia, há também o Fundo de Assistência Jurídica da Corte. Esse Fundo existe para facilitar o acesso das pessoas que tenham petição a fazer, mas não têm recursos para apresentar tal petição. Ele existe como mecanismo para subsidiar defesas e fortalecer o exercício da Corte. Além disso, há também a figura do defensor público interamericano, que pode ser uma pessoa ou grupo de pessoas. O defensor é designado em cada caso para auxiliar as supostas vítimas que não possuem representação legal.

A atuação contenciosa da Corte deve ser fundar na denúncia de alguma violação à Convenção Interamericana de Direitos Humanos perpetrada por um Estado que reconheça sua jurisdição. Ressalte-se que um dos primeiros pontos da atuação da Corte, nesse sentido, trata da análise prévia de sua competência para atuar no contencioso, observando se os Estados envolvidos são partes legítimas, se a matéria trazida enquadra-se como uma violação ao Pacto de San José e se há competência temporal para julgar a violação apresentada.

Uma vez que a Corte lida com Estados que reconheceram sua jurisdição em períodos distintos, muitas vezes admitindo que ela atuasse analisando atos anteriores à data do reconhecimento, bem como investiga crimes que não se esgotam na data de sua ocorrência, mas

\footnotetext{
${ }_{4}$ Regulamento da Corte Interamericana de Direitos Humanos de novembro de 2009. Disponível em: http://www.corteidh. or.cr/sitios/reglamento/nov_2009_por.pdf
} 
se perpetuam até o presente, a confirmação de sua competência temporal é bastante importante para legitimar sua atuação. Há, entre a jurisprudência da Corte, um grande número de decisões que tratam de exceções preliminares sobre tal temática aduzidas pelos Estados.

Conforme analisado, é possível que um Estado acione diretamente a Corte por alguma violação realizada por outro Estado, mas, devido à estrutura de funcionamento do Sistema Interamericano, é habitual observar o acionamento da Corte ocorrendo mediante a atuação da Comissão Interamericana. Quando a Corte Interamericana age mediante provocação da Comissão, ela aproveita as investigações feitas e o relatório emitido pela Comissão, de modo a tornar mais célere o processo. Caso a denúncia tenha partido de um Estado, ela poderá realizar investigações preliminares e buscar explicações dos Estados envolvidos para instruir sua decisão.

Importante frisar que, conforme mencionado, o Sistema Interamericano baseia-se na ideia de prévio esgotamento dos recursos internos. Isso significa que, em caso de violação de direitos humanos, deve haver uma tentativa prévia de solução da questão dentro do Estado para que a matéria possa ser levada ao âmbito interamericano.

A noção de esgotamento dos recursos internos tem sido objeto de ampla análise hermenêutica nas últimas décadas, de modo que, atualmente, admite-se que esse esgotamento requer que os recursos internos sejam meios hábeis a solucionar a violação, não se limitando a meios meramente protelatórios que afastem as garantias dos indivíduos. Assim, não raro, a atuação da Corte Interamericana investiga a atuação dos tribunais internos na busca de solução à violação a ela apresentada. Nesse contexto, a Corte expressa, em suas sentenças, a sua relação com os Tribunais internos, exemplo disso pode ser observado no seguinte trecho de importante decisão sua perante o Estado chileno:

123. A descrita obrigação legislativa do artigo 2o. da Convenção tem também a finalidade de facilitar a função do poder Judiciário de tal forma que o aplicador da lei tenha uma opção clara de como resolver um caso particular. No entanto, quando o Legislativo falha em sua tarefa de cumprir e/ou não adotar leis contrárias à Convenção Americana, o Judiciário permanece vinculado ao dever de garantia estabelecido no artigo $1.1 \mathrm{da}$ mesma e, conseqüentemente, deve abster-se de aplicar qualquer normativa contrária a ela. O cumprimento por parte de agentes ou funcionários do Estado de uma lei violadora da Convenção produz responsabilidade internacional do Estado, e é um princípio básico do direito da responsabilidade internacional do Estado, coletado no Direito Internacional dos Direitos Humanos, no sentido de que todo Estado é internacionalmente responsável por seus atos ou omissões de quaisquer de seus poderes ou órgãos em violações dos direitos internacionalmente consagrados, segundo o artigo 1.1 da Convenção Americana

124. A Corte é consciente que os juízes e tribunais internos estão sujeitos ao império da lei e, por isso, estão obrigados a aplicar as disposições vigentes no ordenamento jurídico. Porém quando um Estado ratifica um tratado internacional como a Convenção Americana, seus juízes, como parte do aparato do Estado, também estão submetidos a ela, o que os obriga a velar para que os efeitos das disposições da Convenção não se vejam esvaziadas pela aplicação de leis contrárias a seu objeto e fim, que desde o início carecem de efeitos jurídicos. Em outras palavras, o Poder Judiciário deve exercer uma espécie de "controle de convencionalidade" entre as normas jurídicas internas que aplicam nos casos concretos e a Convenção Americana sobre Direitos Humanos. Nesta tarefa, o poder 
Judiciário deve considerar não apenas o tratado, mas também a interpretação do mesmo que tenha feito a Corte Interamericana, intérprete última da Convenção Americana (Tradução nossa). ${ }^{5}$

Essa decisão, inclusive, traz importante ponto para a doutrina interamericana, ao abordar a necessidade de aplicação do controle de convencionalidade das normas internas perante as convenções de direitos humanos, ponto que será abordado com maiores detalhes no tópico seguinte.

Para além disso, a sentença da Corte pode concordar com a atuação adotada pelo Estado, demonstrando que foram utilizados os meios adequados para fazer cumprir o Pacto de San José. Contrariamente, pode também observar ter havido uma violação ao Pacto, de modo a emitir uma sentença condenatória ao Estado. Caso condenatória, a decisão da Corte determinará a adoção, pelo Estado agressor, de medidas que façam cessar a violação e restaurar o direito, além de poder condenar o Estado agressor ao pagamento de indenização.

Existem três tipos de sentença: as exceções preliminares, que questionam admissibilidade de uma demanda ou competência do Tribunal para conhecer determinado caso; a decisão de mérito, julgando a ocorrência ou não de violação à Convenção Interamericana e, por fim, caso a decisão de mérito seja condenatória, a Corte poderá emitir uma decisão de reparações e custas. O conteúdo das reparações vai além de uma simples obrigação pecuniária, buscando um resultado que possa reparar os efeitos das violações cometidas. É o que afirma Victor Bazán ao analisar que

(...) o Tribunal Interamericano tem estabelecido que as reparações consistem nas medidas que tendem a fazer desaparecer os efeitos das violações cometidas, adicionando que sua natureza e seu montante dependem do dano ocasionado nos planos tanto material como imaterial (...) $\left(2015\right.$, p. 29 , tradução nossa). ${ }^{6}$

\footnotetext{
Corte Interamericana de Direitos Humanos. Caso Almonacid Arellano e outros vs Chile, sentença de 26 de dezembro de 2006. p. 642, 643. Disponível em: http://www.corteidh.or.cr/docs/resumen/almonacid_arellano.pdf. No original: "123. La descrita obligación legislativa del artículo 2o. de la Convención tiene también la finalidad de facilitar la función del poder Judicial de tal forma que el aplicador de la ley tenga una opción clara de cómo resolver un caso particular. Sin embargo, cuando el Legislativo falla en su tarea de suprimir y/o no adoptar leyes contrarias a la Convención americana, el Judicial permanece vinculado al deber de garantía establecido en el artículo 1.1 de la misma y, consecuentemente, debe abstenerse de aplicar cualquier normativa contraria a ella. El cumplimiento por parte de agentes o funcionarios del Estado de una ley violatoria de la Convención produce responsabilidad internacional del Estado, y es un principio básico del derecho de la responsabilidad internacional del Estado, recogido en el Derecho Internacional de los Derechos Humanos, en el sentido de que todo Estado es internacionalmente responsable por actos $u$ omisiones de cualesquiera de sus poderes $u$ órganos en violación de los derechos internacionalmente consagrados, según el artículo 1.1 de la Convención Americana. 124. La Corte es consciente que los jueces y tribunales internos están sujetos al imperio de la ley y, por ello, están obligados a aplicar las disposiciones vigentes en el ordenamiento jurídico. Pero cuando un Estado ha ratificado un tratado internacional como la Convención Americana, sus jueces, como parte del aparato del Estado, también están sometidos a ella, lo que les obliga a velar porque los efectos de las disposiciones de la Convención no se vean mermadas por la aplicación de leyes contrarias a su objeto y fin, y que desde un inicio carecen de efectos jurídicos. En otras palabras, el Poder Judicial debe ejercer una especie de "control de convencionalidad" entre las normas jurídicas internas que aplican en los casos concretos y la Convención Americana sobre Derechos Humanos. En esta tarea, el Poder Judicial debe tener en cuenta no solamente el tratado, sino también la interpretación que del mismo ha hecho la Corte Interamericana, intérprete última de la Convención Americana".

6 No original: “(...) el Tribunal Interamericano tiene establecido que las reparaciones consisten en las medidas que tienden a hacer desaparecer los efectos de las violaciones cometidas; añadiendo que su naturaleza y su monto dependen del daño ocasionado en los planos tanto material como inmaterial (...)".
} 
O cumprimento da sentença deve ser voluntário, mas é importante notar que as sentenças da Corte são internacionais, as quais, ao contrário das sentenças estrangeiras, não requerem qualquer processo de internalização. Assim, observa-se que a atuação da Corte Interamericana de Direitos Humanos possui grande impacto perante os Estados americanos. Não apenas por emitir decisões vinculantes, que obrigam as partes condenadas a cessar a violação e pagar eventuais reparações pecuniárias, bem como adotar medidas adequadas para reparar os danos sofridos pelos indivíduos, mas também por analisar as decisões dos mais altos Tribunais Nacionais em matéria de direitos humanos.

Não há hierarquia entre a instância nacional e o Tribunal Internacional. Verifica-se, porém, que a Corte Interamericana é o interprete maior do Pacto de San José, de modo que sua interpretação da relação deste com os ordenamentos jurídicos nacionais é essencial para o bom funcionamento do Sistema Interamericano de Proteção de Direitos Humanos. A função de intérprete dos ordenamentos jurídicos nacionais cabe às Cortes constitucionais de cada país, as quais, não raro, são também a última instância de decisão nacional em matéria de direitos humanos.

É inescapável a interação entre a Corte Interamericana e as Cortes nacionais, de modo que, à medida que a Corte robustece sua atuação e fortalece uma jurisprudência em matéria de direitos humanos no continente americano, há uma necessidade cada vez maior dos ordenamentos jurídicos nacionais da região em se aproximar dessa Corte. Desse modo, a influência da Corte Interamericana no contexto regional tem estimulado um diálogo cada vez maior com as Cortes constitucionais americanas, conforme assinala Marcelo Neves:

Nesse contexto, não se trata simplesmente da imposição de decisões da Corte Interamericana de Direitos Humanos (CIDH), criada e estruturada pelo Capítulo VIII (arts. 52 a 69) da CADH, aos tribunais nacionais com competências constitucionais. Esses também reveem a sua jurisprudência à luz das decisões da Corte. Tanto do lado da CIDH quanto da parte das cortes estatais tem havido uma disposição de diálogo em questões constitucionais comuns referentes à proteção dos direitos humanos, de tal maneira que se amplia a aplicação do direito convencional pelos tribunais domésticos (2009, p. 144-145).

Um dos pontos de profunda análise na atuação da Corte Interamericana é a forma com que ela busca garantir o cumprimento das normas convencionais interamericanas por parte dos Estados partícipes do sistema. Sobre essa temática, foi consolidada a ideia do controle de convencionalidade, o qual, inicialmente, foi aduzido em um caso concreto por parte da Corte, no supramencionado Caso Almonacid Arellano e outros Vs. Chile, como obrigação dos Estados em adequar suas normas, práticas administrativas e decisões às convenções americanas de direitos humanos, tendo se consolidado como ferramenta essencial para o funcionamento do Sistema Interamericano.

Por certo, a correta aplicação do controle de convencionalidade ainda é motivo de muito debate não apenas dentro dos Estados, mas mesmo na jurisprudência da Corte Interamericana, por vezes havendo posicionamentos bastante divergentes entre os diferentes atores acerca dos seus limites e aplicabilidade. Ainda assim, é função da Corte, como órgão do Sistema Interamericano, analisar as eventuais incongruências dos ordenamentos nacionais com a lógica do sistema regional. 


\section{CONTROLE DE CONVENCIONALIDADE}

O controle de convencionalidade, abordado inicialmente pelo juiz da Corte Antônio A. Cançado Trindade e consolidado pelo juiz Sergio García Ramírez, é um mecanismo para embasar tanto a atuação da Corte Interamericana quanto dos Estados- partes do Sistema Interamericano nas regras convencionais existentes.

A partir de sua criação, o controle de convencionalidade foi amplamente discutido na doutrina, inclusive buscando definir sua abrangência, níveis de aplicação e técnicas de aplicação. Nesse sentido, conforme traz Mazzuoli:

Falar em controle da convencionalidade significa falar em compatibilidade vertical das normas do direito interno com as convenções internacionais de direitos humanos em vigor no país. Significa, também, falar em técnica judicial de compatibilização vertical das leis com tais preceitos internacionais de direitos humanos (2011, p. 23).

Para além de ser o mecanismo que a Corte utiliza para considerar a validade e aplicabilidade dos atos dos Estados americanos, define bem o funcionamento do controle do convencionalidade Victor Bazán ao afirmar que:

Esse controle convencional exige verificar a congruência das normas jurídicas internas que aqueles (Estados) aplicam nos casos concretos com a Convenção Americana sobre Direitos Humanos (CADH) - entre outros instrumentos internacionais que integram o corpo jurídico interamericano - e os critérios hermenêuticos forjados pela Corte Interamericana de Direitos Humanos (Corte IDH) (2015, p. 27, tradução nossa). ${ }^{7}$

Em verdade, o controle de convencionalidade deve ser verificado por todos os órgãos e setores de um Estado partícipe do Sistema Interamericano. Nesse sentido, mais do que buscar obrigar o Estado genericamente a respeitar o referido controle, a Corte Interamericana evoluiu sua jurisprudência no sentido de buscar diretamente setores específicos dos Estados responsáveis pela não aplicação do referido controle. É o que analisa Manuel Góngora-Mera ao considerar que:

(...) a Corte Interamericana alterou seu esquema tradicional de relacionamento com os países membros do Sistema Interamericano, conhecido na doutrina como o modelo de caixa preta (black-box model). Sob esse esquema, uma vez que a Corte encontrava que um Estado havia violado a Convenção Americana, se limitava a dirigir ordens ao Estado como um todo, sem atribuir obrigações específicas a órgãos estatais. Não obstante, desde o final dos anos noventa, a Corte vem instaurando um modelo de relacionamento direto com órgãos estatais, incluindo o Poder Legislativo e os juízes nacionais (2013, p. 314, tradução nossa). ${ }^{8}$

\footnotetext{
No original: "Ese control convencional exige verificar la congruencia de las normas jurídicas internas que aquellos aplican en casos concretos con la Convención Americana sobre Derechos Humanos (CADH) - entre otros instrumentos internacionales que integran el cuerpo jurídico interamericano - y los criterios hermenéuticos forjados por la Corte Interamericana de Derechos Humanos" (Corte IDH).

8 No original: “(...) la Corte Interamericana ha alterado su esquema tradicional de relacionamiento con los países miembros del sistema interamericano, conocido en la doctrina como el modelo de caja negra (black-box model). Bajo ese esquema, una vez la corte encontraba que un Estado había violado la Convención Americana, se limitaba a dirigir órdenes al Estado como un todo, sin atribuir obligaciones específicas a órganos estatales. Sin embargo, desde finales de los años noventa, la Corte ha venido instaurando un modelo de relacionamiento directo con órganos estatales, incluyendo el poder legislativo y los jueces nacionales".
} 
Ademais da importância de buscar que órgãos dos poderes Legislativo, Executivo e Judiciário apliquem o controle de convencionalidade, por uma escolha epistemológica o presente estudo busca focar-se na realização do controle por parte de Tribunais internos, considerando em que situações há uma maior fluidez ou rigidez na aplicação do mesmo.

É sabido que nem sempre há uma coordenação na atuação dos Tribunais internos e das Cortes Internacionais de Direitos Humanos, especialmente no que se refere à aplicação e abrangência do controle de convencionalidade. Isso porque, não raro, as Cortes dos países consideram demasiadamente invasivas as aplicações de tal controle, enquanto, por outro lado, Cortes Internacionais verificam que, muitas vezes, os Tribunais internos furtam-se de aplicar o controle de convencionalidade, ou o fazem aquém do esperado.

A aparente contradição nessas interpretações leva a um questionamento acerca da efetiva sintonia entre os ordenamentos jurídicos e o Sistema Interamericano de Proteção de Direitos Humanos. A racionalidade entre os sistemas pressupõe que haja uma coordenação na atuação dos distintos atores, principalmente no que se refere à interpretação das normas convencionais existentes.

Quando não há essa coordenação, existe não somente a incompatibilidade na conduta entre os elementos dos sistemas, mas mesmo um risco de fragmentação na relação intersistêmica. Em verdade, é possível ver pontos de conexão capazes de construir pontes de conexão entre os sistemas, porém aspectos não apenas jurídicos, mas também políticos e culturais, influenciam as tomadas de decisão nos diversos âmbitos. Assim, é necessário analisar quais fatores embasam a conexão entre sistemas constitucionais diversos, ainda mais sistemas de estruturas diversas, como o ordenamento jurídico nacional e o sistema regional de direitos humanos, bem como quais os desafios decorrentes da estruturação e funcionamento desses sistemas para sua efetiva harmonização.

Nesse contexto é possível, numa simplificação metodológica das inúmeras formas de interação entre sistemas, apontar três cenários bastante distintos da relação entre as normas convencionais interamericanas e as normas nacionais e como tais cenários dificultam ou facilitam a efetivação do controle de convencionalidade por parte dos Estados. Inicialmente será abordado o cenário no qual os distintos sistemas são herméticos, autônomos e sem pontos aparentes de interseção. Em seguida, numa abordagem mais internacionalista, analisar-se-á o cenário em que sistemas nacionais são enquadrados dentro de um sistema internacional regional maior, configurando-se como verdadeiros subsistemas da esfera internacional. Por fim, será considerada a situação na qual há pontos específicos de interseção entre os sistemas e como diferentes posições de normas dentro de cada sistema podem afetar a realização do controle de convencionalidade.

\subsection{Controle de Convencionalidade quando não há interseção direta entre sistemas}

Em grande medida, apesar da evolução das temáticas internacionais e de direitos humanos, principalmente no pós-Guerras e surgimento da ONU, diversos Estados possuem ressalvas, via de regra embasadas em argumentos de proteção de soberania e autonomia institucional, a considerar as normas e diretivas de sistemas jurídicos internacionais como elementos diretamente integrantes de seus ordenamentos jurídicos. Tal cenário não deixa de ser 
verdade em matéria de direitos humanos, posto que, não raro, há um descompasso entre a profundidade e abrangência da tratativa da matéria no contexto internacional e a real dimensão dos direitos humanos dentro dos Estados nacionais.

É nessa situação, de uma completa distinção entre as normas que surgem no Sistema Interamericano de Direitos Humanos, formando um conjunto normativo próprio, e as existentes no Sistema de Direitos Humanos nacional de cada Estado, em um outro conjunto distinto, que se pode verificar uma ausência de interseções direta entre os sistemas. É o que representa a imagem a seguir:

Figura 1 - Ausência de Interseção Direta entre Sistemas

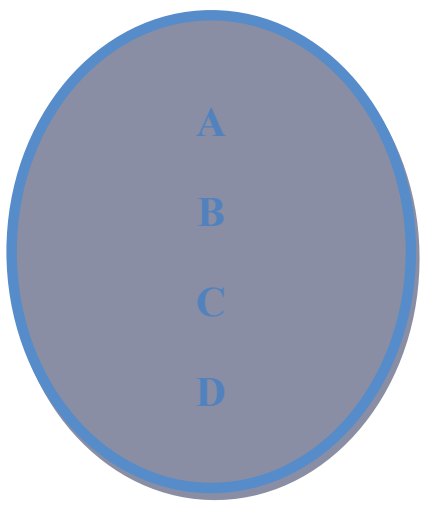

Sistema Interamericano

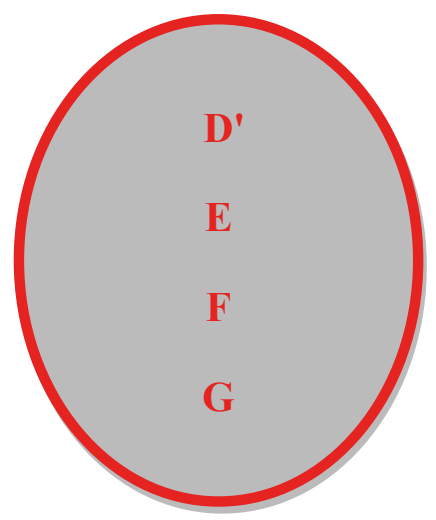

Sistema nacional

Fonte: Os autores.

Diz-se ausência de interseção direta porque, conforme exibido na imagem, não há uma superposição entre os dois conjuntos, sendo cada sistema hermético e autopoiético, o que não exclui, porém, a possibilidade de surgimento de elementos de conexão que permitam a reprodução ou o conhecimento de um conjunto de normas e regras de outro. Ainda assim, ressalte-se, não há uma construção conjunta entre os sistemas, apenas a possibilidade de uma reprodução em maior ou menor grau similar de um elemento de um em outro.

É o que é demonstrado na imagem por meio da presença do elemento «D» no Sistema Interamericano e do elemento "D»" no sistema nacional. A norma interamericana pode até ter sido reproduzida no âmbito nacional, por exemplo por meio de um processo de internalização comum aos países que praticam o dualismo, porém não é possível afirmar, de plano, que se trata da mesma norma ipsis litteris, pois, no processo de reprodução, há uma ressignificação do conteúdo da norma para se adequar ao conjunto normativo nacional. Assim, é até possível que haja uma reprodução literal do texto normativo, porém a sua interpretação e aplicação pode ser bastante alterada pela prática já existente no ordenamento nacional.

Esse cenário apresenta uma grande dificuldade para a realização do controle de convencionalidade. Isso porque, conforme exposto na imagem, não há uma interseção que permita ao ordenamento jurídico nacional aplicar as normas convencionais considerando todo o Sistema Interamericano, de modo que os Tribunais nacionais têm uma grande tendência a rejeitar 
a aplicação do controle de convencionalidade, por considerar uma imposição de normas alienígenas, fora do conjunto normativo nacional e cujas observações e aplicações pertencem a um conjunto exógeno e estranho.

Por outro lado, no caminho inverso, a atuação da Corte na aplicação do controle de convencionalidade tende a priorizar muito mais a análise sistêmica tomando por base, primariamente, o Sistema Interamericano, o que pode gerar certa incapacidade em reconhecer realidades e particularidades do sistema nacional, contribuindo mais ainda para que suas decisões pareçam imposições alienígenas aos Tribunais nacionais.

Em verdade, apesar de tal cenário apontar para uma imensa dificuldade na aplicação do controle de convencionalidade, é bastante difícil verificá-lo em sua totalidade na realidade americana. O próprio processo de formação e consolidação do Sistema Interamericano, conforme mencionado anteriormente, assim como os mecanismos existentes para aproximar os Estados do contexto regional de direitos humanos, como as opiniões consultivas, garantem que, na prática, não ocorra uma completa ausência de interseção entre os sistemas.

Apesar de algumas críticas e posições mais extremadas de alguns Estados apontarem para um cenário como o da Figura 1, o mesmo seria insustentável numa interação entre sistemas, tendendo muito mais a uma fragmentação intersistêmica, em que cada conjunto afasta-se definitivamente do outro, como seria exemplo de uma saída de um Estado do Sistema Interamericano. A existência de canais de diálogo converge para uma aproximação entre os sistemas, de modo a garantir que haja, em maior ou menor medida, uma interseção entre ambos. Essa interseção pode ser tão intensa e verificada em tal grau que se torna possível cogitar a completa inclusão de um sistema no outro, conforme visto no cenário a seguir.

\subsection{Controle de Convencionalidade quando um sistema é subsistema de outro}

Os sistemas internacionais, e o Sistema Interamericano de Direitos Humanos não é exceção, são sistemas que incidem em uma multitude de Estados e com uma abrangência que, algumas vezes, permite considerar a sua existência como uma superestrutura, englobando seus Estados integrantes. Não por acaso, no período de expansão e consolidação das Organizações Internacionais e dos sistemas jurídicos internacionais, principalmente com o final do período de guerra fria, foram retomadas ideias de supersistemas, que não apenas interagem com os sistemas nacionais, mas, em certa medida, sobrepõem-se a eles.

Nesse cenário, em matéria de direitos humanos e na evolução do Sistema Interamericano, parte da doutrina internacional passou a ressaltar a importância de considerar as normas convencionais interamericanas como aquelas que, por suas características e maneiras de formulação, estariam automaticamente integradas a qualquer Estado que fosse parte do Sistema Interamericano, bem como, na via inversa, todo o ordenamento jurídico de todos os Estados membros seria também englobado dentro do Sistema Interamericano, podendo ser verificada a validade e aplicabilidade de suas normas perante o contexto convencional regional.

É o que se observa na imagem a seguir, que representa: 
Figura 2 - Sobreposição do Sistema Interamericano sobre o Sistema Nacional

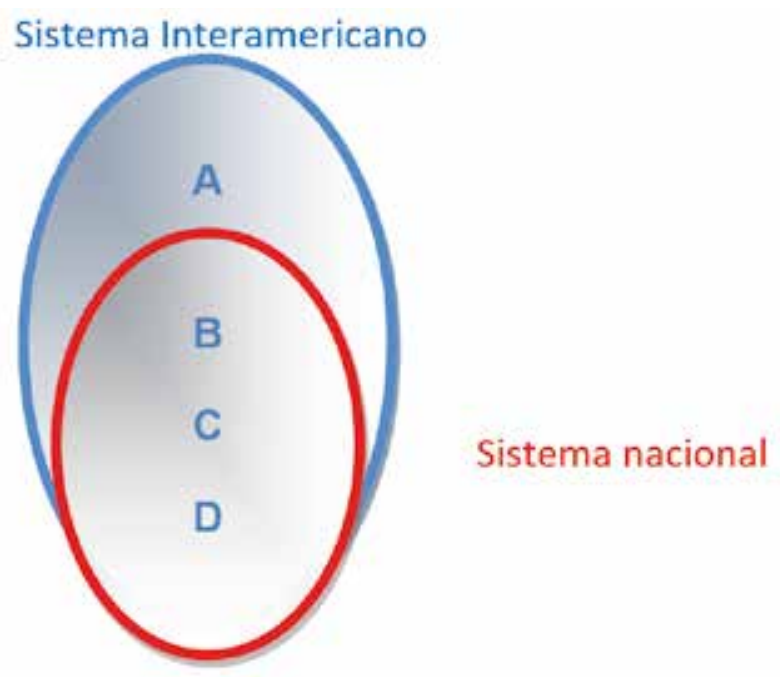

Fonte: Os autores.

Percebe-se, portanto, que o Sistema Interamericano surgiria para envolver todo o sistema nacional. Mais que isso, as próprias normas internas, nesse contexto, também passariam a fazer parte do Sistema Interamericano, na medida em que seriam passíveis de verificação e interpretação por parte dos órgãos interamericanos, notadamente a Corte, para considerar se estariam adequadas ao conjunto regional. Nesse contexto, o ordenamento jurídico nacional torna-se verdadeiro subconjunto do Sistema Interamericano na temática de direitos humanos, de modo que deve haver uma plena harmonia normativa para seu funcionamento.

Esse cenário é o de mais fácil verificação da aplicabilidade do controle de convencionalidade. Ao envolver todo o sistema nacional, o Sistema Interamericano consegue fazer uma análise de convencionalidade direta de todas as normas presentes e um eventual descompasso que existiria dentro do ordenamento nacional deve, necessariamente, ser corrigido ou ocasionar a extinção da norma de ambos os sistemas. A atuação da Corte Interamericana, nesse contexto, tem um caráter bem mais top-down, constituindo-se na intérprete maior das convenções interamericanas e podendo, portanto, rever quase que diretamente a atuação dos Tribunais internos.

Apesar de ser ressaltado como estrutura almejada no contexto regional americano por parte da doutrina, que menciona, inclusive, a capacidade de organismos como a Corte de verificar todas as normas dos ordenamentos jurídicos nacionais, bem como sua competência para emitir opiniões sobre qualquer norma ou tema de direitos humanos que interesse ao contexto regional, a verdade é que esse cenário também é de difícil verificação na realidade americana.

Isso porque verifica-se na prática da Corte Interamericana, apesar da abrangência do Sistema Interamericano, que ela não possui capacidade irrestrita para analisar os ordenamentos jurídicos internos, bem como suas decisões, que apesar de vinculantes, passam por um processo de cumprimento voluntário por parte dos Estados. Assim, mesmo que a Corte considere uma norma interna inválida em relação às regras convencionais, por meio do controle de convencionalidade, caso os Tribunais internos de cada Estado recusem-se a cumprir tal decisão, há pouco que o Sistema Interamericano possa realizar para fazer valer sua interpretação. 
Na prática, portanto, é difícil considerar que os sistemas nacionais de direitos humanos sejam apenas subsistemas do Sistema Interamericano, estando totalmente integrados dentro das normativas convencionais e, portanto, totalmente aptos a serem interpretados pela via do controle de convencionalidade. Se esse é o objetivo final do Sistema Interamericano, conforme parte da doutrina aduz, ainda está longe de ser concretizado.

Verifica-se, portanto, que nenhum dos dois cenários extremos apresentados, ausência total de interseção e inclusão completa como subsistema, parecem reproduzir a realidade atual da interação entre o Sistema interamericano e os nacionais. É possível considerar, desse modo, um caminho intermediário, no qual há interseção entre sistemas, porém ela ocorre em níveis e intensidades bastantes distintas, a depender da norma em questão, do sistema nacional de cada Estado e da jurisprudência consolidada da Corte Interamericana.

\subsection{Controle de Convencionalidade quando há interseção entre sistemas}

Conforme mencionado, é difícil considerar, em termos práticos, os cenários onde os sistemas interamericano e nacional não se conectam em nenhum ponto ou onde eles conectam-se tanto que passam a um fazer parte integralmente do outro. Por outro lado, numa análise intermediária entre esses extremos, é possível considerar o cenário onde há interseção entre sistemas, em menor ou maior grau, e quais seriam os impactos dessa interseção para a aplicação do controle de convencionalidade.

Considerar que os sistemas possuem pontos de interseção direta não implica afirmar que eles não são sistemas autopoiéticos, pois cada sistema é capaz de existir e funcionar de forma autônoma. Em verdade, a interseção aponta mais para um contexto em que as influências das particularidades normativas e jurisprudenciais de um sistema passam a influenciar a formação normativa e jurisprudencial do outro, fazendo com que normas mais semelhantes ao outro sistema tendam a gravitar mais próximo e sejam atraídas ao ponto de interseção, enquanto normas profundamente distintas da realidade do outro sistema permanecem afastadas do centro gravitacional de interseção. É o que pode ser demonstrado na imagem a seguir:

Figura 3 - Interseção entre Sistemas

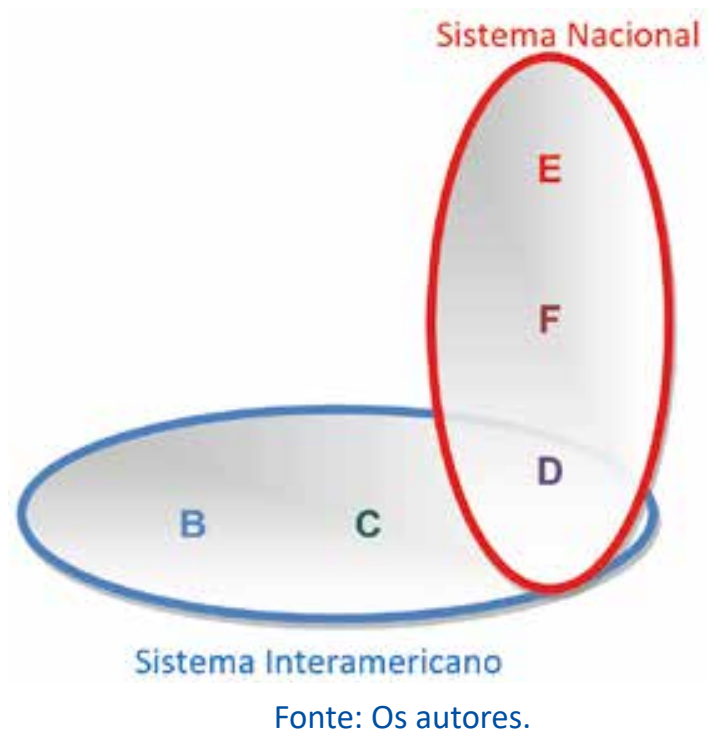


Esse cenário apresenta uma série de situações e particularidades interessantes, as quais influenciam diretamente a aplicação do controle de convencionalidade. Inicialmente, tomando por referência o elemento " $E$ ", presente no sistema nacional, verifica-se que a aplicação do controle de convencionalidade nesse caso estaria muito próxima do cenário de ausência de interseção direta, na qual há uma tendência de a interpretação da norma ser bem mais influenciada pelo contexto do ordenamento jurídico interno e com ressalvas quanto à interpretação conforme as regras convencionais. Seria o caso, por exemplo, de um país com uma legislação bastante soberanista em matéria de Lei de Anistia de regimes de exceção, como foi a tônica em diversos casos no continente americano.

Cenário distinto é o caso do elemento " $\mathrm{F}$ ". A maior proximidade do ponto de interseção entre os sistemas contribui para que a interpretação conforme as normas convencionais seja mais verificável, o que pode ocorrer tanto da própria criação da norma, em um período de aproximação do Sistema Interamericano, quanto com uma paulatina mudança na interpretação jurisprudencial dos Tribunais internos por atração à jurisprudência da Corte Interamericana. Talvez um dos exemplos mais conhecido seja a figura da proibição da prisão civil do depositário infiel, matéria que, inclusive, chegou a ser tratada em normas constitucionais por alguns Estados americanos e passou a ser gradativamente revista, aplicando o controle de convencionalidade para se aproximar da tratativa presente no Pacto de San José da Costa Rica.

De outro plano, pode também o sistema nacional influenciar o Sistema Interamericano e alterar a jurisprudência da Corte, o que se verifica no elemento " $C$ ". Nesse cenário, a aplicação das normas convencionais pode se aproximar da interpretação conferida dentro dos Estados a certos temas, como é o exemplo da interpretação que a Corte Interamericana passou a conferir para o conceito de terras comunitárias, bastante influenciada pelo novo constitucionalismo latino-americano de Estados andinos, com forte representação de populações indígenas.

Por fim, é possível que certas normas surjam ou passem a integrar-se dentro do ponto de interseção entre os sistemas. É o exemplo do elemento " $D$ ", que se distingue do cenário de inclusão de um sistema como subsistema do outro, pois a elaboração e consolidação da norma é resultado de um esforço complementar dos distintos sistemas, em um processo de diálogo que permita o reconhecimento mútuo entre os sistemas de direitos humanos, o que garante a mais fácil aplicação do controle de convencionalidade tanto por parte da Corte quanto dos Tribunais nacionais, que estão cientes da participação do Estado na negociação das normas convencionais e da sua adequação ao restante de seu ordenamento jurídico. Pode-se citar, nesse cenário, iniciativas como as recentes convenções que tratam do combate ao racismo e outras formas de discriminação e intolerância.

Esse cenário de interseção parcial entre os sistemas parece ser o mais verificável na realidade atual do contexto americano. O Sistema Interamericano de Direitos Humanos, sem dúvida, evoluiu bastante nas últimas décadas, principalmente após o fim do período de regimes de exceção no continente americano, passando a interagir e dialogar, cada vez mais, com os sistemas nacionais de direitos humanos. Mesmo assim, a interação e interseção entre 
eles ainda está em processo de consolidação, o que faz com que a efetividade do controle de convencionalidade varie a depender da matéria tratada e do grau de diálogo existente entre os distintos sistemas.

Nesse cenário, é necessário reconhecer as particularidades de cada contexto, sabendo verificar bem qual cenário de interação intersistêmica ocorre in casu, para, desse modo, evitar-se frustrações na aplicação da jurisprudência da Corte Interamericana, bem como garantir a consolidação e expansão da aplicação do controle de convencionalidade por parte dos Estados americanos.

\section{CONSIDERAÇÕES FINAIS}

A temática dos direitos humanos vem ganhando importância no continente americano nas últimas décadas e a crescente participação dos órgãos do Sistema Interamericano de Direitos Humanos tem sido acompanhada por uma interação cada vez mais intensa entre os Estados e seus órgãos. Nesse contexto, é preciso buscar compreender melhor quais os elementos que influenciam a interação intersistêmica entre a Corte Interamericana de Direitos Humanos e os Tribunais internos.

É patente a importância da aplicação do controle de convencionalidade por parte dos Estados, principalmente por seus tribunais internos, para garantir a efetividade das convenções interamericanas, contudo nem sempre é claro qual o melhor caminho para a efetivação de tal controle e quais elementos dificultam a sua aplicação. Não há dúvida, entretanto, de que o diálogo entre os distintos níveis é essencial para o funcionamento do controle de convencionalidade, conforme aponta Victor Bazán ao afirmar que:

Uma significativa via de articulação consiste no traçado de linhas de cooperação dos tribunais internos e a Corte IDH e na prefiguração de um "diálogo judicial" entre eles, de ordem que os órgãos máximos de justiça constitucional dos Estados integrados ao sistema da CADH acatem com os standards fixados pelo Tribunal Interamericano, mas que correlativamente este tenha presente as observações que desde os contextos jurisdicionais nacionais se formulem a seus critérios jurisprudenciais. Isso é assim para fortalecer qualitativamente a tutela multinível dos direitos humanos e diminuir os riscos de eventuais dificuldades no funcionamento concreto do controle de convencionalidade (2015, p. 37-38, tradução nossa). ${ }^{9}$

O acatamento a certos standards fixados pela Corte Interamericana, todavia, não ocorre sempre de forma automática, variando sensivelmente a considerar o grau de interseção e interação intersistêmica existente entre o sistema nacional e o interamericano. Assim, para compreender a real efetividade de uma exigência da Corte para que Tribunais internos apli-

\footnotetext{
9 No original: “Una significativa vía de articulación consiste en el trazado de líneas de cooperación de los tribunales internos y la Corte IDH y en la prefiguración de un "diálogo judicial" entre ellos, en orden a que los órganos máximos de justicia constitucional de los Estados integrados al sistema de la CADH acaten los estándares fijados por el Tribunal Interamericano, pero que correlativamente éste tenga presente las observaciones que desde los contextos jurisdiccionales nacionales se formulen a sus criterios jurisprudenciales. Ello así para fortalecer cualitativamente la tutela multinivel de los derechos humanos y disminuir los riesgos de eventuales dificultades en el funcionamiento concreto del control de convencionalidad".
} 
quem o controle de convencionalidade, é importante saber se há interseção entre a esfera interamericana e a nacional na interpretação da norma alvo do controle e, se houver, qual sua abrangência.

Nesse contexto, apresenta-se, como um cenário mais realista e de fácil verificação a situação da existência de pontos de interseção entre o Sistema Interamericano e os sistemas nacionais de direitos humanos, porém persistindo ainda matérias específicas que são tratadas de maneira bastante diversas pelos distintos sistemas, as quais muitas vezes constituem os maiores desafios para a realização de uma coordenação entre a interpretação da Corte Interamericana e dos Tribunais nacionais. É preciso prosseguir, portanto, com bastante cautela, buscando vislumbrar de maneira bastante clara os distintos cenários, para não frustrar a eficácia do controle de convencionalidade.

É certo que outros fatores influenciam tal eficácia - relativismos culturais, discursos políticos de certos Estados, menor abrangência da temática de direitos humanos nas cortes internas são alguns desses exemplos. É, todavia, um ponto de partida crucial compreender a natureza da relação intersistêmica na matéria específica. Sem isso, é possível que sejam adotadas interpretações bastante abrangentes do controle de convencionalidade por parte da Corte Interamericana que não são acompanhadas pelos Tribunais nacionais, não por uma rejeição da jurisprudência da Corte, mas por uma ausência ou fragilidade da interseção da temática conforme é abordada no âmbito interamericano com a prática nacional.

A eficácia do controle de convencionalidade, portanto, não deve ser fragilizada por níveis distintos de interação intersistêmica. Em verdade, é necessário compreender quais os diferentes cenários apresentados e buscar avançar no diálogo em diversos níveis de maneira adequada, para que tanto sejam respeitadas as recomendações e decisões da Corte Interamericana quanto os Tribunais internos possam reconhecer nas convenções interamericanas elementos comuns a seus ordenamentos, que facilitem seu trabalho hermenêutico.

Toda essa preocupação com a aplicação do controle de convencionalidade está focada no cuidado maior em garantir a aplicação dos direitos humanos da forma mais benéfica possível aos indivíduos. Sabe-se que muito da evolução da temática de direitos humanos, nas últimas décadas, tem sido no sentido de garantir a aplicação das normas mais benéficas aos indivíduos, os quais têm, cada vez mais, protagonismo na esfera internacional. O funcionamento adequado do controle de convencionalidade, portanto, deve servir para garantir mais ainda o acesso desses indivíduos a tais direitos.

Não há solução simples nem interpretação absoluta quando a temática é direitos humanos, muito menos na interação entre seus distintos sistemas, não sendo o Sistema Interamericano de Direitos Humanos exceção nesse cenário. Considerar os distintos graus de interseção entre os sistemas quando da aplicação do controle de convencionalidade, contudo, é uma efetiva ferramenta para evitar surpresas e frustrações na relação entre as diversas cortes envolvidas. 


\section{REFERÊNCIAS}

BAZÁN, Victor. El control de convencionalidad como instrumento para proteger derechos esenciales y prevenir la responsabilidad internacional del Estado. In: Anuario Iberoamericano de Justicia Constitucional, Madrid: Centro de Estudios Políticos y Constitucionales, n. 19, p. 25-70, 2015. Disponible en: http//:dx.doi.org/10.18042/cepc/ aijc.19.02.

CORTE Interamericana de Direitos Humanos. Caso Almonacid Arellano e outros vs Chile, sentença de 26 de dezembro de 2006. Disponível em: http://www.corteidh.or.cr/docs/resumen/almonacid_arellano.pdf. Acesso em: 22 jun. 2018.

CORTE Interamericana de Direitos Humanos. Regulamento da Corte Interamericana de Direitos Humanos de novembro de 2009. Disponível em: http://www.corteidh.or.cr/sitios/reglamento/nov_2009_por.pdf. Acesso em: 21 jun. 2018.

GÓNGORA-MERA, Manuel Eduardo. Interacciones y convergencias entre la Corte Interamericana de Derechos Humanos y los tribunales constitucionales: un enfoque coevolutivo. In: PIOVESAN, Flávia; BOGDANDY, Armin Von; MORALES ANTONIAZZI, Mariela (org.). Estudos avançados de direitos humanos (democracia e integração jurídica: emergência de um novo direito público). Rio de Janeiro: Elsevier, 2013. p. 312-337.

HEWKIN, Louis; PUGH, Richard; SCHACHTER, Oscar; SMIT, Hans. International law: cases and materials. 3. ed. Minnesota: West Publishing, 1993.

HEYNS, Christof, VILJOEN, Frans. An overview of human rights protection in Africa in South African. Journal of Human Rights, v. 11, part. 3, 1999.

KRASNER, Stephen D. Structural causes and regime consequences: regimes as intervening variables in International Regimes. Ithaca: Cornell University Press, spring, 1982.

LUHMANN, Niklas. Sistemas sociais - esboço de uma teoria geral. 1. ed. São Paulo: Vozes, 2016. ().

MAZZUOLI, Valerio de Oliveira. O controle jurisdicional da convencionalidade das leis. Prefácio Luiz Flávio Gomes. 2. ed. rev., atual. e ampl. São Paulo: Editora Revista dos Tribunais, 2011. (Coleção direito e ciências afins; v. 4. Coordenação Alice Bianchini, Luiz Flávio Gomes, William Terra de Oliveira).

NEVES, Marcelo. Transconstitucionalismo. São Paulo: Editora WMF Martins Fontes, 2009.

OEA. Organização dos Estados Americanos. Convenção Americana sobre Direitos Humanos. Disponível em: http://www.oas.org/dil/esp/tratados_B-32_Convencion_Americana_sobre_Derechos_Humanos.pdf. Acesso em: 15 jun. 2018.

PIOVESAN, Flávia Cristina; GOMES, Luiz Flávio; BEVILACQUA, Maria Beatriz Galli; DE MELLO, Monica; PFEIFFER, Roberto Augusto Castellanos. O sistema interamericano de proteção dos direitos humanos e o direito brasileiro. São Paulo: Revista dos Tribunais, 2000.

PIOVESAN, Flávia. A justicialização do sistema interamericano de proteção dos direitos humanos: impacto, desafios e perspectivas. Boletim Científico, ,n. 4, jul./set. 2002. Disponível em: http://boletimcientifico.esmpu.gov.br/ boletins/boletim-cientifico-n.-4-2013-julho-setembro-de-2002/a-justicializacao-do-sistema-interamericano-de-protecao-dos-direitos-humanos-impacto-desafios-e-perspectivas. Acesso em: 29 jun. 2018.

PIOVESAN, Flávia. Direitos humanos e o direito constitucional internacional. 14. ed., rev. e atual. São Paulo: Saraiva, 2013. 